6 - ORIGINAL ARTICLE

ISCHEMIA-REPERFUSION

\title{
Effect of allopurinol on the kidney function, histology and injury biomarker (NGAL, IL-18) levels in uninephrectomised rats subjected to ischaemia-reperfusion injury ${ }^{1}$
}

\author{
André Roberto Bussmann', Marcos Antônio Marton Filho"I, Marília Pinheiro Módolo ${ }^{\mathrm{II}}$, Renata Pinheiro Módolo ${ }^{\mathrm{III}}$, Patrícia \\ AmadoII, Maria Aparecida Custódio Domingues ${ }^{\text {IV }}$, Yara Marcondes Machado Castigliav, Norma Sueli Pinheiro Módolov \\ DOI: http://dx.doi.org/10.1590/S0102-86502014000800006 \\ IFellow Master degree, Postgraduate Program in Anaesthesiology, Botucatu Medical School, Sao Paulo State University (UNESP), Botucatu-SP, \\ Brazil. Intellectual and scientific content of the study, design the protocol, technical procedures, acquisition and interpretation of data, statistical \\ analysis, manuscript writing.

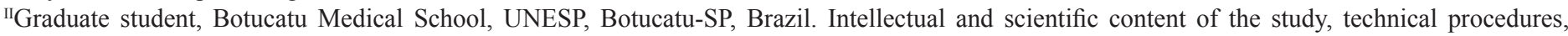 \\ acquisition of data.

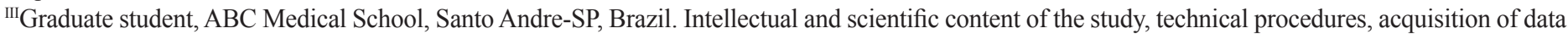 \\ ${ }^{\text {Iv }} \mathrm{PhD}$, Assistant Professor, Department of Pathology, Botucatu Medical School, UNESP, Botucatu-SP, Brazil. Histopathological analysis. \\ ${ }^{v} \mathrm{PhD}$, Full Professor, Department of Anaesthesiology, Botucatu Medical School, UNESP, Botucatu-SP, Brazil. Intellectual and scientific content of the \\ study, design the protocol, manuscript writing, supervised all phases of the study, critical revision.
}

\section{ABSTRACT}

PURPOSE: To investigate whether allopurinol exerts a protective effect on kidneys by measuring new kidney injury biomarkers (NGALp, NGALu, KIM-1 and IL-18) and analysing the renal function and histology in uninephrectomised rats subjected to ischaemia-reperfusion injury. METHODS: Thirty two Wistar rats were randomly allocated to four groups: Sham (S): laparotomy; Control (C): laparotomy and ischaemia-reperfusion in the left kidney; Control Allopurinol (CA): laparotomy and allopurinol at a dose of $100 \mathrm{mg}^{\cdot} \mathrm{kg}^{-1} \cdot \mathrm{d}^{-1}$; and Allopurinol (A): laparotomy ischaemia-reperfusion in the left kidney and allopurinol at a dose of $100 \mathrm{mg} \cdot \mathrm{kg}^{-1} \cdot \mathrm{d}^{-1}$. The NGALp, $\mathrm{NGALu}$, KIM-1, IL-18 and creatinine levels and the kidney histology were analysed. The significance level was established as $\mathrm{p}<0.05$.

RESULTS: Creatinine level increased in all the groups, with $\mathrm{A} \approx \mathrm{C}>\mathrm{S} \approx \mathrm{CA}$. The NGALp, NGALu and IL-18 levels exhibited similar behaviour in all the groups. KIM-1 was higher in group A than C and showed intermediate values in groups S and CA. Severity of injury in the left kidney was greater in groups $\mathrm{C}$ and $\mathrm{A}$ compared to $\mathrm{S}$ and $\mathrm{CA}$.

CONCLUSION: Allopurinol did not exert protective or damaging effects on the kidneys of rats subjected to ischaemia-reperfusion injury. Key words: Ischemia. Acute Kidney Injury. Allopurinol. Interleukin-18. Biomarkers, Pharmacological. Rats. 


\section{Introduction}

Changes in renal function are common in severe diseases. In spite of the advances in recent years, mortality and morbidity rates remain high, reaching $60 \%{ }^{1}$. In the renal form, acute tubular necrosis accounts for $75 \%$ of the cases of acute kidney injury (AKI). In $47.5 \%$ of patients AKI was was associated with septic shock, the most frequent cause, followed by postoperative complications $(34 \%)$, cardiogenic shock (27\%), hypovolaemia $(26 \%)$ and the use of nephrotoxic drugs $(19 \%)^{1}$.

During ischaemia, adenosine triphosphate (ATP) is degraded to adenosine, inosine, hypoxanthine and xanthine. Xanthine dehydrogenase $(\mathrm{XD})$ is converted to xanthine oxidase $(\mathrm{XO})$ as a result of the overload of intracellular calcium induced by ischaemia. At the stage of reperfusion of the ischaemic tissue, the conversion of accumulated hypoxanthine into xanthine, which is catalysed by the enzyme $\mathrm{XO}$, results in the production of reactive oxygen species (ROS), including superoxide $\left(\mathrm{O}_{2}^{-}\right)$, hydrogen peroxide $\left(\mathrm{H}_{2} \mathrm{O}_{2}\right)$ and hydroxyl radicals $\left(\mathrm{OH}^{-}\right)^{2}$. The damage to the renal tubule cells caused by ROS is mediated by protein oxidation, lipid peroxidation, DNA damage and the induction of apoptosis. Peroxidation of membrane phospholipids results in increased cell permeability, which might cause changes in renal function and histology ${ }^{3}$.

Molecular changes induced by kidney injury precede both cell damage and the development of clinical manifestations. Therefore, the detection of biomarkers might contribute to the early diagnosis of $\mathrm{AKI}^{4}$. New kidney injury biomarkers were recently developed. The concentrations of Neutrophil Gelatinase-Associated Lipocalin (NGAL) in the urine (NGALu) and plasma (NGALp), as well as the urine concentration of interleukin-18 (IL-8), have been used as potential early biomarkers of AKI.

According to some studies, allopurinol and its active metabolite oxipurinol exhibit a protective effect against myocardial ischaemia-reperfusion injury ${ }^{5}$. The specific mechanism underlying this effect has not yet been elucidated; however, it is believed to involve the inhibition of $\mathrm{XO}^{6}$

The aim of the present study was to establish whether allopurinol exerts a protective effect on the kidneys by analysing new kidney injury biomarkers and the renal function and histology in uninephrectomised rats subjected to ischaemia-reperfusion injury.

\section{Methods}

The use of laboratory animals follow the Council for International Organization of Medical Sciences (CIOMS) and was approved by the Animal Experimentation Ethics Committee of the School of Medicine of Botucatu, 32 male Wistar rats, aged eight weeks and weighing 300-500g were supplied by the Central Vivarium of Sao Paulo State University (UNESP), and were included in the study. The animals were all kept in captivity under the same environmental and nutritional conditions. The rats were kept in sawdust-lined cages $(47 \times 34$ x $18 \mathrm{~cm}$; four animals per cage) in one room at a constant temperature $\left(22 \pm 2^{\circ} \mathrm{C}\right)$, with light from 7:00 to 19:00h and water and food ad libitum.

\section{Experimental protocol}

The animals were randomly allocated into four groups: Sham (S n = 8): laparotomy and right-sided nephrectomy; Control ( $\mathrm{C} \mathrm{n}=8$ ): laparotomy, right-sided nephrectomy, ischaemiareperfusion manoeuvres and placebo; Control Allopurinol $(\mathrm{CA} \mathrm{n}=$ 8): laparotomy, right-sided nephrectomy and $100 \mathrm{mg} \cdot \mathrm{kg}^{-1} \cdot \mathrm{d}^{-1}$ oral allopurinol 24 hours and one hour before the start of the experiment; and Allopurinol (A $\mathrm{n}=8$ ): laparotomy, right-sided nephrectomy, ischaemia-reperfusion manoeuvres and $100 \mathrm{mg} \cdot \mathrm{kg}^{-1} \cdot \mathrm{d}^{-1}$ oral allopurinol 24 hours and one hour before the start of the experiment.

Twenty-four hours before the start of the experiment, the animals were placed in individual metabolic cages. Urine samples for tests (T0) were collected from the cages immediately before the animals were anaesthetised. Anaesthesia was performed with isoflurane (calibrated Ohmeda IsoTec 5 vaporiser) under inhalational induction, with invasive mean arterial pressure (MAP) and rectal temperature monitoring. Following catheterisation of the right internal jugular vein and the left carotid artery, as well as the collection of blood samples (T0), a right-sided nephrectomy was performed. In the groups subjected to ischaemia, the left kidney pedicle was exposed, and the blood flow was interrupted for 30 minutes using an atraumatic vascular clamp. Reperfusion was established by removing the clamp. After thirty minutes of reperfusion, blood samples were collected (T1). The abdominal wall was closed, and analgesia was performed with $0.15 \%$ subcutaneous bupivacaine at the incision site. The animals' body temperature was kept at $36-38^{\circ} \mathrm{C}$ throughout the experiment using thermal packs; fluid replacement was performed with 3 $\mathrm{mL} \cdot \mathrm{kg}^{-1} \cdot \mathrm{h}^{-1}$ lactated Ringer's solution using an infusion pump $\left(\mathrm{ANNE}^{\circledR} / \mathrm{ABBOTT}\right.$ - Brazil). After the animals woke up, they were kept in metabolic cages to collect urine samples 24 hours after reperfusion (T2); the cages were equipped with a device that separated the food, stools and water from the urine. The animals were then anaesthetised again, blood samples were collected (T2), the left kidneys were removed for later analysis and the animals were sacrificed. 


\section{Blood tests}

The creatinine concentration was measured by spectrophotometry using EBRAM $^{\circledR}$ (Brazil) reagents and a COBAS MIRA PLUS ${ }^{\circledR}$ - ROCHE device. The NGALp, NGALu and IL-18 concentrations were measured by enzyme-linked immunosorbent assay (ELISA) using standard kits from BioPorto Diagnosis A/S (Denmark).

\section{Histopathology}

Both the right and left kidneys were subjected to histopathological analysis. For that purpose, fresh tissue was fixed with a Duboscq-Brasil solution (6 mL of $40 \%$ formaldehyde, 12 $\mathrm{mL}$ of absolute alcohol, $1.5 \mathrm{~mL}$ of acetic acid and $8 \mathrm{~mL}$ of picric acid) for 48 hours and then placed in $70 \%$ alcohol. The histological slides were stained with hematoxylin and eosin and analysed by optical microscopy. The histological analysis was performed by a pathologist blinded to the groups to which the kidneys belonged. Kidney necrosis was graded according to Park et al. ${ }^{7}$ as follows: 0 - normal; 1 - mild (<10\%); 2 - moderate (10-25\%); 3 - moderate to severe $(25-50 \%) ; 4$ - severe $(50-75 \%) ; 5$ - very severe $(>75 \%)$.

\section{Statistical analysis}

Comparisons between groups were performed by oneway analysis of variance (ANOVA) for repeated measures and contrast analysis. Kruskal-Wallis ANOVA and Dunn's multiple comparison test were used to compare the rats' weights and histological grades of injury. The analyses were performed using the SAS 6.11 software (SAS Institute, Inc., Cary, NC). The significance level was established as $\mathrm{p}<0.05$.

\section{Results}

The samples exhibited a homogenous distribution, with the variable weight yielding $\mathrm{p}=0.14$ (Table 1 ).

TABLE 1 - Weight (grams).

\begin{tabular}{ccccc}
\hline Group & $\mathrm{n}$ & mean & SD & $p$ value \\
\hline C & 8 & 451.3 & 43.9 & \\
S & 8 & 400 & 45 & \\
CA & 8 & 425 & 52.9 & 0.14 \\
A & 8 & 395 & 60.4 & \\
\hline
\end{tabular}

Kruskal-Wallis analysis of variance

SD: Standart Deviation

\section{Blood tests}

The serum creatinine levels (Figure 1) and the NGALp values (Figure 2A) exhibited significant increases in all the groups over the course of the experiment. One-way ANOVA and contrast analysis determined that the NGALp levels exhibited a similar progression, without significant differences among the groups.

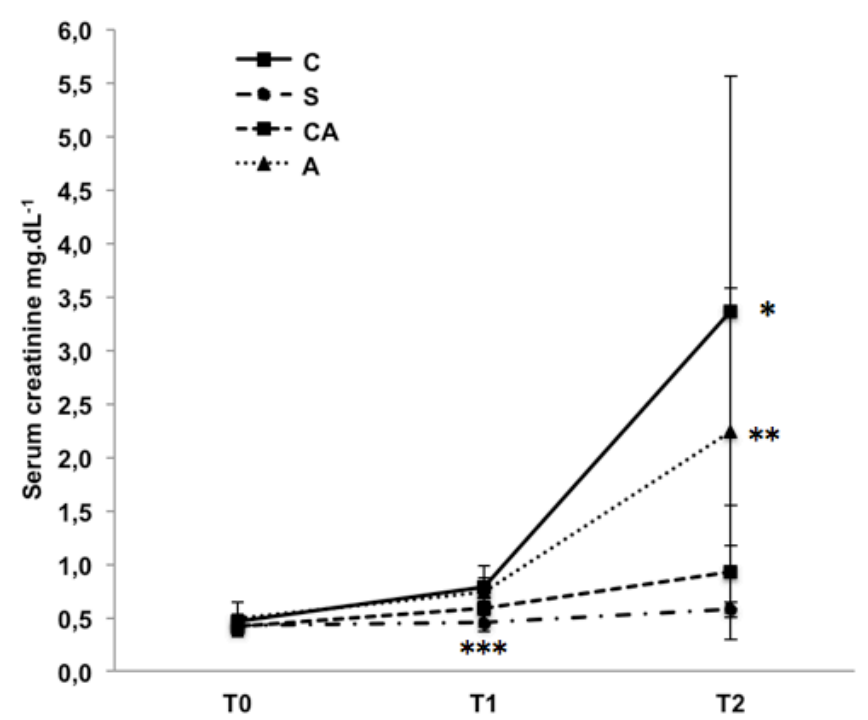

FIGURE 1 - Effect of allopurinol on the serum creatinine levels $\left(\mathrm{mg} \cdot \mathrm{dL}^{-1}\right) * \mathrm{p}=0.001$ in comparison with groups $\mathrm{S}$ and $\mathrm{CA} \cdot{ }^{* *} \mathrm{p}=0.001$ in comparison with group $\mathrm{S}$ (tendency toward A $>\mathrm{CA}$ ). ${ }^{* * *} \mathrm{p}=0.009$ in comparison with groups $\mathrm{C}, \mathrm{A}$ and CA. One-way ANOVA for repeated measures was conducted. Each marker represents the mean \pm standard deviation.

\section{Urine tests}

The four groups exhibited similar variations in the NGALu levels without significant differences among them (Figure 2B). The IL-18 level was significantly increased in all of the groups over the course of the experiment and the contrast analysis showed that all four groups exhibited similar behaviour (Figure 2C). 

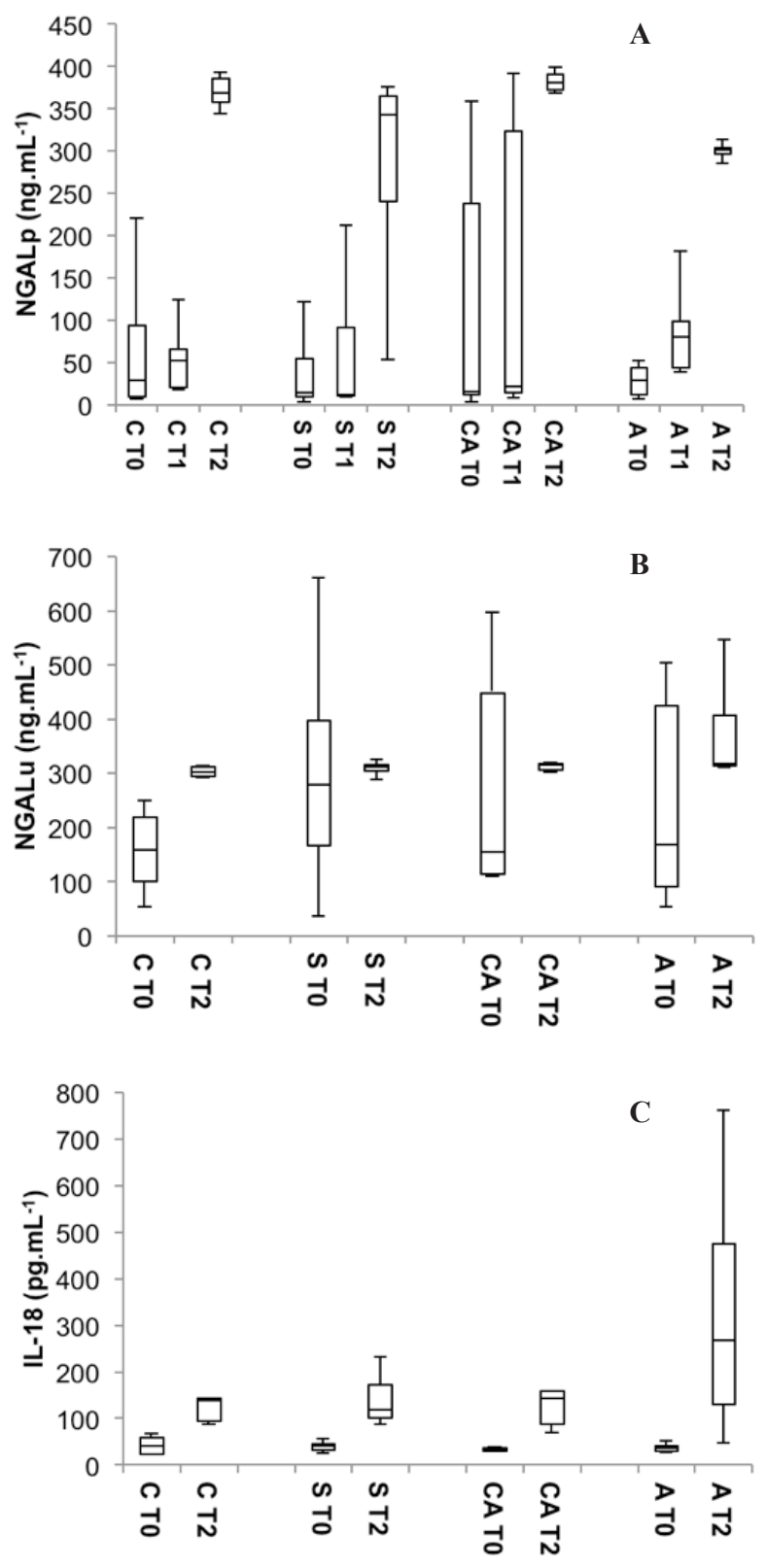

FIGURE 2 - A) NGALp levels throughout the experiment. Time point pairs: T0-T1 $\mathrm{p}=0.42$; $\mathrm{T} 0-\mathrm{T} 2 \mathrm{p}=0.99$; $\mathrm{T} 1-\mathrm{T} 2 \mathrm{p}=0.50 . \mathrm{C} \approx \mathrm{S} \approx \mathrm{CA} \approx \mathrm{A}$ for all time point pairs. B) NGALu levels throughout the experiment. Time point pairs: $\mathrm{T} 0-\mathrm{T} 2 \mathrm{p}=0.46(\mathrm{C} \approx \mathrm{S} \approx \mathrm{CA} \approx \mathrm{A})$. C) IL-18 levels throughout the experiment. Time point pairs: $\mathrm{T} 0-\mathrm{T} 2 \mathrm{p}=0.16(\mathrm{C} \approx \mathrm{S}$ $\approx \mathrm{CA} \approx \mathrm{A}$ ). One-way ANOVA for repeated measures and contrast analysis was conducted.

\section{Histological analysis}

The histological analysis of the right kidneys did not show differences among the groups, none of which exhibited kidney injury. The degree of injury was significantly greater in groups $\mathrm{C}$ and A compared to $\mathrm{S}$ and CA. Significant differences were not found between groups $\mathrm{C}$ and $\mathrm{A}$ or between $\mathrm{S}$ and $\mathrm{CA}$ (Figure 3).

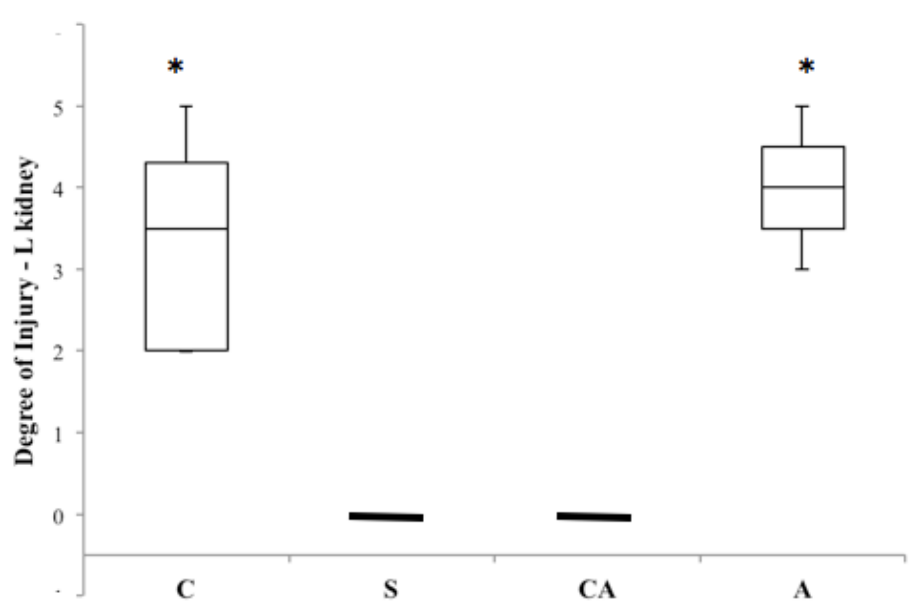

FIGURE 3 - Degree of histological injury in the left kidney according to Park's criteria.

The statistical analyses included Kruskal-Wallis analysis of variance and Dunn's multiple comparisons test. * $\mathrm{p}=0.0002$ compared to groups S and AC.

\section{Discussion}

The ischaemia time exerts a direct influence on the plasma creatinine levels and the degree of kidney injury. The plasma creatinine levels exhibited a two-fold increase after 25 minutes of ischaemia and a seven- to eight-fold increase after 45 minutes, which is associated with significant necrosis ( $>75 \%)$. In the present study, a period of 30 minutes of ischaemia was selected because it had been used in previous studies to induce moderate kidney ischaemic injury ${ }^{8}$. Massive necrosis would have hindered histological analysis According to a recent study, an analysis of the NGALu levels showed that 30 minutes is the ideal duration of ischaemia to achieve the peak level of kidney injury ${ }^{9}$.

Right-sided nephrectomy was performed because earlier studies showed that unilateral nephrectomy is associated with quicker recovery from kidney failure, less ischaemic injury and a greater production of humoral factors that stimulate compensatory renal responses ${ }^{8}$.

All the animals were anaesthetised using isoflurane, as in a previous study, and the creatinine level and the degree of renal necrosis were lower in the rats administered volatile anaesthetics during ischaemia-reperfusion. Isoflurane was associated with a reduction in inflammation and thus in kidney damage through modulation of leukocytes (neutrophils, macrophages and natural killer $1.1+$ cells) and early T-lymphocyte influx ${ }^{10}$.

The progression of kidney injury was similar in both groups subjected to ischaemia-reperfusion $(\mathrm{A} \approx \mathrm{C})$, which was 
characterised by a progressive increase in the serum creatinine level and histological damage. The variables NGALp, NGALu, IL-18 and creatinine did not exhibit an interaction effect, as the p-values were $>0.05$ in all cases, thus indicating that allopurinol did not exert a protective effect.

In groups $\mathrm{S}$ and $\mathrm{CA}$, the plasma creatinine levels exhibited increases in the longitudinal analysis. However, those increases, as a rule, were smaller compared to the groups subjected to ischaemia. None of the biomarkers assessed exhibited differences, i.e., the patterns of NGALp, NGALu and IL-18 were similar in groups $\mathrm{S}$ and $\mathrm{CA}$. Those findings indicate that allopurinol does not cause kidney injury by itself.

It was initially hypothesised that the protective effect of allopurinol in ischaemic tissues occurs through the inhibition of free radical formation during oxidative stress. One of the approaches used to quantify oxidative stress in vivo consists of measuring the 8-isoprostane levels. In Wang et al. ${ }^{11}$ study, such levels significantly increased after 60 minutes of only ischaemia, while they did not change significantly after 15, 30 and 45 minutes. In that study, the authors compared the 8-isoprostane levels between two groups of rats subjected to 30 minutes of reperfusion after a period of 60 minutes of renal ischaemia, one of which was given $100 \mathrm{mg} \cdot \mathrm{kg}^{-1}$ intravenous allopurinol, while the other group received no treatment. The 8-isoprostane levels were lower in the group treated with allopurinol, thus denoting a reduction in oxidative stress in that group. A later study by Keel et $a l .{ }^{6}$ reported similar findings, which led us to believe that the protective effect of allopurinol manifests when ischaemia lasts longer than 60 minutes.

Rhoden et $a .^{2}$ conducted an ischaemia-reperfusion study in an animal model in which the authors sought to establish whether allopurinol behaves as a protective factor. In that study, rats were subjected to right-sided nephrectomy seven days before ischaemia manoeuvres were performed. One of the groups subjected to ischaemia was given $50 \mathrm{mg} \cdot \mathrm{kg}^{-1} \cdot \mathrm{d}^{-1}$ intraperitoneal allopurinol five hours and one hour before the induction of ischaemia, while the other group served as a control. The increase in the serum creatinine level was attenuated in the group treated with allopurinol, as was the decrease in the creatinine clearance 24 and 96 hours after reperfusion. Those authors further found reductions in the levels of lipid peroxidation in the treated groups, thus pointing to a protective effect of allopurinol through the reductions in cell protein and lipid damage.

In another one-kidney model, the left kidneys of two groups of rats, one pre-treated with intravenous allopurinol and the other left untreated, were subjected to 15, 30 and 60 minutes of ischaemia, and the NGALu levels were measured 30, 45 and 60 minutes after reperfusion. The increase in the NGALu levels was smaller in the pre-treated group subjected to ischaemia for more than 30 minutes at all of the reperfusion time points compared with the untreated group 9 .

In the histological analysis, injury was not found in the right kidneys of the animals in any group. The left kidney did not exhibit injury in groups $\mathrm{S}$ and $\mathrm{CA}$, which agrees with the findings reported by Rhoden et al. ${ }^{2}$ Conversely, $100 \%$ of the animals in groups $\mathrm{C}$ and A exhibited kidney injury of varying degree, the median scores being 3.5 and 4 points higher, respectively, compared to groups S and CA. Groups $\mathrm{C}$ and A were not different from each other, nor were $\mathrm{S}$ and CA. Similar to the findings related to renal function, allopurinol did not exhibit a protective effect against renal ischaemia-reperfusion injury from the histological point of view.

The abovementioned study by Rhoden et $a .^{2}$ found kidney injury in all the animals subjected to ischaemia, while the degree of injury 24 hours after reperfusion was similar in both groups. The histological analysis performed eight days after reperfusion showed tubular atrophy and interstitial fibrosis in both groups; however, the group treated with allopurinol differed, thus pointing to a protective effect of that drug. These results indicate that the protective effect of allopurinol as assessed by the degree of histological injury might only be detected eight days after reperfusion.

The Risk, Injury, and Failure; Loss; and End-stage kidney disease (RIFLE) ${ }^{12}$ and Acute Kidney Injury Network $(\mathrm{AKIN})^{13}$ criteria were formulated to create a uniform definition of AKI for diagnostic purposes. To characterise the various features of the disease, identify individuals at risk and introduce preclinical treatments, the Acute Dialysis Quality Initiative (ADQI) 10 consensus recommended modifying the AKIN/RIFLE criteria to include biomarkers of kidney damage for the diagnosis and risk stratification of individuals with $\mathrm{AKI}^{14}$.

A recent literature review found that the area under the receiver operating characteristics curve (AURoC) for the diagnosis of AKI using the biomarkers in the paediatric population ranged from 0.44 to 1.00 , the positive predictive value (PPV) ranged from $27 \%$ to $100 \%$ and the negative predictive value (NPV) ranged from $10 \%$ to $100 \%$. Among adults after cardiac surgery, the AURoC ranged from 0.27 to 0.98 , the PPV ranged from $4 \%$ and $100 \%$ and the NPV ranged from $61 \%$ to $100 \%$. The AURoC of the biomarkers assessed in patients assisted in the emergency unit ranged from 0.59 and 0.95 , the PPV ranged from $4 \%$ and $90 \%$ and the NPV ranged from $84 \%$ to $99.5 \%$. Finally, among the patients 
admitted to intensive care units, the AURoC ranged from 0.35 to 0.99 , the PPV ranged from $1 \%$ and $100 \%$ and the NPV ranged from $50 \%$ to $100 \%{ }^{15}$.

Regarding the diagnostic usefulness of the biomarkers, the results of studies are quite disparate, ranging from remarkably negative to extremely optimistic. The earliest clinical studies using biomarkers showed promising results associated with high PPV in homogenous populations with an acute, single and easily identifiable cause of potential kidney damage, such as extracorporeal circulation and the use of intravenous contrast media. Most biomarkers are not only associated with kidney damage but also with other conditions that might lead to AKI. In heterogeneous populations with multifactorial causes of AKI, the performance of biomarkers in the early diagnosis of kidney damage proved to be similar to clinical assessments and standard laboratory tests. The NGALu and IL-18 levels were shown to be higher among septic children compared with non-septic children, thus indicating that the association between NGALu/IL-18 levels and AKI in septic patients might reflect the severity of disease rather than actual kidney damage ${ }^{16,17}$.

There is clearly an overlapping area characterised by variable degrees of the coexistence of functional and histological AKI. A recent study showed that markers of tubular damage might be present even in cases of transient AKI, such as AKI associated with volume depletion, thus indicating that 'functional' and 'strutural'AKI can be graded on a single continuum ${ }^{18}$. In the prospective study by Singer et al. ${ }^{19}$, the ability of NGALu to distinguish between prerenal and intrinsic AKI was tested based on the response to fluid resuscitation. A differential diagnosis was successfully attained in only $25 \%$ of the cases.

The use of biomarkers should be assessed cautiously, as although most studies found changes in their values in individuals with AKI, there is a substantial overlap of the concentrations exhibited by individuals with and without kidney injury. This overlap makes the classification of individual cases difficult. In regard to the diagnosis of subclinical AKI, one study showed that the discriminating ability of NGALu decreases as the RIFLE class decreases $^{20}$. In addition, the basic assumption in the literature is that increases in the biomarker levels not accompanied by a concomitant increase in the serum creatinine concentration are indicative of AKI. As a result, the sensitivity of the method increases at the expense of its specificity and PPV.

It is generally believed that most of the new biomarkers of kidney injury are able to detect AKI earlier compared to the measurement of the creatinine level; however, the relationship between the patterns of increase and renal damage is not yet fully understood.
The use of biomarkers should be validated within the clinical contexts in which they will be used, because the performance of each biomarker may vary depending on the clinical setting. Regarding clinical applications, the degree of subclinical injury indicated by increases in the biomarker levels alone must still be established. For that purpose, studies assessing the correlation between the elevation of biomarker levels and long-term outcomes are needed.

\section{Conclusion}

The use of allopurinol at a dose of $100 \mathrm{mg} \cdot \mathrm{kg}^{-1} \cdot \mathrm{d}^{-1} \mathrm{did}$ not exert beneficial effects on ischaemia-reperfusion injury as assessed by histological analysis and measurements of creatinine and new biomarker (NGALu, NGALp and IL-18) levels.

\section{References}

1. Uchino S, Kellum JA, Bellomo R, Doig GS, Morimatsu H, Morgera S, Schetz M, Tan I, Bouman C, Macedo M, Gibney N, Tolwani A, Ronco C. Acute renal failure in critically ill patients: a multinational, multicenter study. JAMA 2005 Aug17;294(7):813-8. doi: 10.1001/ jama.294.7.813.

2. Rhoden E, Teloken C, Lucas M, Rhoden C, Mauri M, Zettler C, Adriane Bello'-Klein A, Barros E. Protective effect of allopurinol in the renal ischemia--reperfusion in uninephrectomized rats. Gen Pharmacol. 2000 Oct;35(4):189-93. PMID: 11827725.

3. Devarajan P. Update on mechanisms of ischemic acute kidney injury. J Am Soc Nephrol. 2006 Jun;17(6):1503-20. doi: 10.1681/ ASN.2006010017.

4. Soni SS, Ronco C, Katz N, Cruz DN. Early diagnosis of acute kidney injury: the promise of novel biomarkers. Blood Purif. 2009;28(3):165-74. doi: 10.1159/000227785.

5. Lee BE, Toledo AH, Anaya-Prado R, Roach RR, Toledo-Pereyra LH. Allopurinol, xanthine oxidase, and cardiac ischemia. J Investig Med. 2009 Dec;57(8):902-9. doi: 10.231/JIM.0b013e3181bca50c.

6. Keel CE, Wang Z, Colli J, Grossman L, Majid D, Lee BR. Protective effects of reducing renal ischemia-reperfusion injury during renal hilar clamping: use of allopurinol as a nephroprotective agent. Urology. 2013 Jan;81(1):210.e5-10. doi: 10.1016/j. urology.2012.08.016.

7. Park Y, Hirose R, Dang K, Xu F, Behrends M, Tan V, Roberts JP, Niemann CU. Increased severity of renal ischemia-reperfusion injury with venous clamping compared to arterial clamping in a rat model. Surgery. 2008 Feb;143(2):243-51. doi: 10.1016/j. surg.2007.07.041.

8. Modolo NS, Castiglia YM, Ganem EM, Braz JR, Vianna PT, Vane LA. Acute renal ischemia model in dogs: effects of metoprolol. Ren Fail. 2001 Jan;23(1):1-10. PMID: 11256518.

9. Woodson B, Wang L, Mandava S, Lee BR. Urinary cystatin C and NGAL as early biomarkers for assessment of renal ischemiareperfusion injury: a serum marker to replace creatinine? J Endourol. 2013 Sep;27(12):1-6. doi: 10.1089/end.2013-0198.ECB13.

10. Lee HT, Kim M, Kim M, Kim N, Billings FT, D’Agati VD, Emala $\mathrm{CH}$. Isoflurane protects against renal ischemia and reperfusion injury and modulates leukocyte infiltration in mice. Am J Physiol Renal Physiol. 2007 Sep;293(3):F713-22. doi: 10.1089/end.20130198.ECB13. 
11. Wang Z, Colli JL, Keel C, Bailey K, Grossman L, Majid D, Lee BR. Isoprostane: quantitation of renal ischemia and reperfusion injury after renal artery clamping in an animal model. J Endourol. 2012 Jan;26(1):21-5. doi: 10.1089/end.2011.0188.

12. Bellomo R, Ronco C, Kellum JA, Mehta RL, Palevsky P. Acute renal failure - definition, outcome measures, animal models, fluid therapy and information technology needs: the Second International Consensus Conference of the Acute Dialysis Quality Initiative (ADQI) Group. Crit Care. 2004 Aug;8(4):R204-12. doi: 10.1186/ cc2872.

13. Mehta RL, Kellum JA, Shah SV, Molitoris BA, Ronco C, Warnock DG, Levin A. Acute Kidney Injury Network: report of an initiative to improve outcomes in acute kidney injury. Crit Care. 2007;11(2):R31-R38. doi: 10.1186/cc5713.

14. McCullough PA, Shaw AD, Haase M, Bouchard J, Waikar SS, Siew ED, Murray PT, Mehta RL, Ronco C. Diagnosis of acute kidney injury using functional and injury biomarkers: workgroup statements from the tenth Acute Dialysis Quality Initiative Consensus Conference. Contrib Nephrol. 2013;182:13-29. doi: 10.1159/000349963.

15. Vanmassenhove J, Vanholder R, Nagler E, Van Biesen W. Urinary and serum biomarkers for the diagnosis of acute kidney injury: an in-depth review of the literature. Nephrol Dial Transplant. 2013 Feb;28(2):254-73. doi: 10.1093/ndt/gfs380.

16. Washburn KK, Zappitelli M, Arikan AA, Loftis L, Yalavarthy R, Parikh CR, Edelstein CL, Goldstein SL. Urinary interleukin-18 is an acute kidney injury biomarker in critically ill children. Nephrol Dial Transplant. 2008 Feb;23(2):566-72. doi: 10.1093/ndt/gfm638.

17. Wheeler DS, Devarajan P, Ma Q, Harmon K, Monaco M, Cvijanovich N, Hong HR. Serum neutrophil gelatinase-associated lipocalin (NGAL) as a marker of acute kidney injury in critically ill children with septic shock. Crit Care Med. 2008 Apr;36(4):1297303. doi: 10.1097/CCM.0b013e318169245a.

18. Nejat M, Pickering JW, Devarajan P, Bonventre JV, Edelstein $\mathrm{CL}$, Walker RJ, Endre ZH. Some biomarkers of acute kidney injury are increased in pre-renal acute injury. Kidney Int. 2012 Jun;81(12):1254-62. doi: 10.1038/ki.2012.23.
19. Singer E, Elger A, Elitok S, Kettritz R, Nickolas TL, Barasch J, Luft FC, Schmidt-Ott KM. Urinary neutrophil gelatinase-associated lipocalin distinguishes pre-renal from intrinsic renal failure and predicts outcomes. Kidney Int. 2011 Aug;80(4):405-14. doi: 10.1038/ki.2011.41

20. Haase-Fielitz A, Bellomo R, Devarajan P, Bennett M, Story D, Matalanis G, Frei U, Dragun D, Haase M. The predictive performance of plasma neutrophil gelatinase-associated lipocalin (NGAL) increases with grade of acute kidney injury. Nephrol Dial Transplant. 2009 Nov;24(11):3349-54. doi: 10.1093/ndt/gfp234.

\section{Correspondence:}

Norma Sueli Pinheiro Módolo

Departamento de Anestesiologia

Faculdade de Medicina de Botucatu - UNESP

Distrito de Rubião Jr, s/n

Caixa Postal 530

18618-970 Botucatu - SP Brasil

nmodolo@fmb.unesp.br

Received: Mar 26, 2014

Review: May 27, 2014

Accepted: Jun 25, 2014

Conflict of interest: none

Financial source: Sao Paulo Research Foundation (FAPESP - grant \#12/13604-9)

${ }^{1}$ Research performed at Laboratory of Experimental Surgery, School of Medicine of Botucatu, State University of Sao Paulo (UNESP), Brazil. Part of Master degree thesis, Postgraduate Program in Anaesthesiology. Tutor: Norma Sueli Pinheiro Módolo. 